\title{
EL CAPITEL CORINTIO DE HOJAS LISAS EN COLONIA PATRICIA CORDUBA
}

\author{
Carlos MARQUEZ MORENO (*)
}

Si ya resulta problemático determinar con criterios rígidos el desarrollo del capitel corintio normal en el que la talla y forma de la hoja y del resto de elementos tienen una importancia destacada, más lo es el intentar periodizar un capitel que no cuenta con estos componentes.

No es otro el caso del capitel de hojas lisas.

Dos son los grupos que hay que distinguir dentro de este tipo; por un lado el formado por aquellas piezas o partes que no se labran porque iban a ocupar lugares poco visibles que hacían innecesario el acabado de las hojas y por otro el grupo de aquellas que, como consecuencia de una evolución autónoma, se individualizan del capitel corintio-normal y pasan a crear un nuevo tipo: el capitel de hojas lisas. Será de este último del que nos ocupemos en este trabajo en el que expondremos también dos ejemplos de capiteles semielaborados en los que se puede analizar someramente la técnica de su elaboración.

Esta separación se realiza en el siglo II d.C. Antes del mencionado siglo, sólo en Roma y Palmira se ha atestiguado la presencia de este capitel (CRESSEDI 1952. HARRAZI 1982, 118).

En el siglo III los capiteles de hojas lisas forman ya un tipo independiente del capitel corintio-normal. Si, como dijimos, antes eran concebidos como capiteles canónicos a los que les faltaba la última talla, a partir de este siglo comienzan a poseer una autonomía respecto al corintio normal (PENSABENE 1973,387), a pesar de lo cual mantiene unas vinculaciones lógicas con él.

Su difusión en la Península Ibérica es amplia, encontrándose en Itálica, Sevilla, Sagunto, Tarragona, Barcelona, Mérida, Lugo, Vila Viçosa, Estremoz y Conimbriga (GUTIERREZ BEHEMERID 1982, 39; 1986, 57 y Mapa 5; BARRERA 1984, 56; DIAZ MARTOS 1985; RECASENS, 1979, 43 ss.; CHINER 1990, 85).

(*) Universidad de Córdoba. 
El uso al que se destinaba este tipo era muy variado, aunque siempre en un ámbito de construcción doméstica, suficientemente atestiguado en el $\mathrm{N}$. de Africa, o bien pública con carácter lúdico, expansivo o comercial, tal es el caso de las termas, de los anfiteatros y de los mercados (como el de Sertio en Timgad), aunque no falta la excepción en esta regla representado, por ejemplo, en piezas empleadas en el Recinto Sacro de Largo Argentina en Roma y en la Via delle Bothege Oscure (COARELLI, 1981, 18, lám. VI).

Las piezas presentes en este trabajo pueden por un lado demostrarnos cuál ha sido la evolución interna de este tipo en la producción de una capital de provincia romana, Colonia Patricia Corduba a la vez que ayudarnos a confirmar los datos que, en lo que respecta a la técnica de elaboración y acabado de elementos arquitectónicos, conocemos en la actualidad. Hemos de decir que los ejemplares ahora analizados no representan la totalidad de piezas de este tipo concreto en Córdoba (en total son 17 los ejemplares hallados hasta el momento) y que sólo son la muestra de su desarrollo tipológico.

Hacíamos alusión con anterioridad a la dificultad de asignar criterios válidos para la catalogación de este tipo de capiteles. En este contexto es en el que debemos aludir a los argumentos expuestos por $\mathrm{N}$. Harrazi por los que considera arriesgado fechar estas piezas (HARRAZI 1982,117), para concluir que, si bien en líneas generalès somos de la misma opinión, nuestro criterio varía en los siguientes términos:

1. El estudio de los capiteles corintios con hojas labradas es, efectivamente un paralelo magnífico a la hora de estudiar las hojas lisas; y ya hemos aludido a la espléndida colección de capiteles corintios de hojas labradas con la que cuenta la capital de la Bética.

2. Los talleres locales participan de caracteres comunes bien trabajen uno u otro tipo de capitel. A modo de ejemplo diremos que el no abandono absoluto de la decoración en la zona libre del kalathos durante el siglo III (característica de la que participa la producción de los talleres cordobeses), es algo que se observa indistintamente en hojas lisas y en capiteles corintio-canónicos.

3. La autonomía e independencia de los talleres locales -desde nuestro punto de vista y experiencia, toda vez que conocemos los factores de su evolución- ayuda más que perjudica a fechar las piezas, si bien de una forma relativa al no contar con los datos topográficos y arqueológicos. Es más, resultaría arriesgado hacer un uso excesivo de los paralelos alejados geográficamente dado que esto entra en contradicción en ocasiones con el desarrollo autónomo de los talleres locales.

En definitiva, opinamos que es correcto llevar a cabo un estudio centrado en el capitel de hojas lisas en Córdoba como elemento integrante y peculiar de la arquitectura romana en la ciudad. Por otro lado el número de piezas con el que contamos es suficiente para la realización de este estudio y demuestra unas transformaciones que en muchos casos pueden ser observadas (y corroboradas) también en los capiteles corintio-normales.

Iniciamos el estudio presentando dos ejemplares de capiteles corintios semielaborados (Lámina I), alguno de cuyos lados y hojas se encuentra sin labrar. Los hemos fechado 
en la segunda mitad del siglo II y pueden ayudarnos a entender de qué forma culminaba el proceso de labra de un capitel corintio. Al analizar detenidamente el ejemplar $\mathrm{n}^{\mathrm{Q}} 1$ (Lámina I, Números 1-A y 1B) vemos cómo uno de los lados del capitel se encuentra sin el proceso final. Efectivamente, observamos que si bien ciertos elementos del mismo tales como las hojas se encuentran a falta de la última fase que consistiría en el diseño y posterior vaciado de los lobulos y hojitas, la mitad superior no ha superado ni tan siquiera la segunda fase de elaboración, esto es, el desbaste mediante el cual los diferentes componentes del capitel comienzan a tener una forma concreta. Así, se observa que la zona que ocupará posteriormente la voluta no es más que un paralelepípedo donde se pueden aún observar las improntas del puntero. Lo mismo sucede en el caso de la zona ocupada por la flor de ábaco y el cáliz que adorna el kálathos. El caso del segundo capitel es distinto (Lámina I, Número 2-A y 2-B). En él se nota ya toda la zona perfectamente labrada a falta sólo de la última fase en el proceso, esto es, dibujo de los elementos vegetales y su consiguiente elaboración, consistente en el caso de la zona libre del kalathos en el vaciado de toda la zona a fin de dejar en relieve el cáliz que es, en el caso que nos ocupa, el motivo de su decoración.

Muy cercano al final del siglo II o a comienzos del siguiente, se fecharía el grupo de capiteles formado por los números 3,4 y 5 (Lámina II), pertenecientes plenamente al tipo corintio de hojas lisas y cuyas características son tan similares que creemos puedan formar parte de un mismo edificio. Lamentable resulta ignorar su procedencia ya que se trata de un material reaprovechado en la Mezquita; en ellos vemos ya un acortamiento de la zona libre del kalathos respecto a los dos primeros ejemplares, aunque sigue adornándose con el mismo motivo en los cuatro casos: un cáliz abierto en cuyo centro se alza el tallo de la flor de ábaco. Los caulículos comienzan ya a perder un volumen que, curiosamente, volverá a recuperar en algún ejemplar tardío; las hélices, que se tocan, comienzan ya a notar el peso del ábaco y consiguientemente a inclinarse ligeramente. Todo ello nos remite, por paralelos hallados en Ostia y Peruggia (vid. Catálogo) y por el propio desarrollo del orden corintio en la ciudad de Córdoba a un momento de transición entre los siglos II y III d.C.

Por las razones vistas con anterioridad, resulta imposible en el actual estado de los conocimientos, asignar este grupo a un edificio concreto.

Las siguientes muestras anuncian ya, de forma clara, su asignaciónal siglo III (Lámina III, números 7, 8,9 y 10): las hélices se encuentran ya completamente oprimidas por el peso del ábaco, peso que en periodos anteriores soportaba con una verticalidad considerable pero que en este momento obliga a las mismas, primero a inclinarse cada vez más, por lo que acusa de manera cada vez más notable su horizontalidad y su relación con las volutas; segundo, incluso a perder parte del extremo superior de su roleo. Junto a esto, una característica de los talleres cordobeses es que no abandonan la decoración de la zona libre del $\mathrm{ka}$ lathos en el siglo III, sino que ocupan dicho espacio con una hoja lisa acanalada en el eje. 
También puede observarse el relieve cada vez más escaso de las volutas que, en ocasiones, y para separar la boquilla del resto de la pieza, se limita a ser tallada por dos estrechos y poco profundos canales horizontales.

A partir del siglo IV se observa una abstracción, pérdida del naturalismo y una conclusión del proceso, en definitiva, del que hemos venido haciendo referencia: eliminación de la decoración en la zona libre del kalathos; los caulículos se han convertido en elementos casi planos; las piezas tienden a adoptar una forma acampanada; hélices y volutas son ya una la continuación de la otra en una línea horizontal; en una palabra, la simplificación llevada a sus extremos (Lámina IV, números 11,12 y 13).

$\mathrm{El}$ análisis de material nos conduce a unas conclusiones necesariamente generales. Observamos que el mayor número de piezas fechadas en el siglo III son de mármol, algunas de ellas incluso pertenecerían con seguridad a un mismo edificio aunque su ubicación actual en la Mezquita supone un impedimento para conocer su origen. Este siglo representa para Córdoba, a tenor de la documentación arqueológica conocida centrada en el estudio de sus casas (SECILLA-MARQUEZ 1988) un momento de notable auge constructivo si bien, repito, sólo puede hacerse extensivo en el estado actual de los conocimientos a la arquitectura doméstica, a la cual pertenecería la mayor parte de los ejemplares presentes en este estudio. Tal hipótesis se ve confirmada con la proliferación notabilísima de capiteles corintios trabajados de esta ciudad, cuyo estudio hemos realizado en los últimos años (MARQUEZ 1990), adscritos cronológicamente al siglo III; además, veánse los resultados de las últimas intervenciones arqueológicas en Córdoba (VENTURA 1991; BERMUDEZ, VENTURA, MARFIL, GONZALEZ, 1991), que son las que realmente pueden confirmar mediante el método estratigrafico tales aseveraciones.

Hemos visto de forma práctica cómo el estudio de este tipo de capitel se ha realizado a través de una óptica tipológica más que estilística. Y es a través de ese criterio que podemos observar notables concomitancias con regiones cercanas a la Bética; así, vemos cómo los capiteles de hojas lisas del resto de la Península Ibérica participan, grosso modo en las características expuestas, de la misma forma que lo hacen aquellas piezas analizadas en el Africa romana. Se diferencian, sin embargo, de los ejemplares estudiados en Italia (PENSABENE 1972). Tal criterio lo basamos al centrar nuestra atención en la decoración de la zona libre del kalathos, donde se observa que en aquellos ejemplares peninsulares fuera de las fronteras de la Bética no conservan esta decoración durante el siglo III, lo mismo que no lo hacen en la mayor parte de los ejemplares italianos. Sí lo hacen, sin embargo, en la zona norteafricana, donde contamos con ejemplos claramente asignables al siglo III en Cesarea de Mauritania (PENSABENE 1982) y Bulla Regia (láminas Vy VI, procedentes de la Casa de la Caza y de la Casa del Anfítrite, similares los n ${ }^{o t} 14$ y 16 al grupo cordobés ubicado en la Mezquita), todo lo cual nos hace creer en la existencia de contactos directos entre estas dos regiones, hipótesis que fue ya someramente analizada por Thouvenot (THOUVENOT 1938) y que creemos se confirma con el análisis de las 
piezas que hemos presentado. No resulta difícil de imaginar estos contactos si pensamos en la cercanía geográfica de Cherchel y en la característica de ser el puerto más cercano a la Bética, desde donde habría, consiguientemente no sólo un trasiego comercial basado en el aceite, vino, trigo, cerámica y otros productos sino también centrado en una visión artística común.

\section{Catalogo}

\section{Número 1}

Material: Mármol.

Localización: Mezquita.

Medidas: Altura: $45 \mathrm{~cm}$. Abaco: $7 \mathrm{~cm}$. Segunda corona: $24 \mathrm{~cm}$. Corona infer.: $14 \mathrm{~cm}$.

Capitel corintio de columna en el que se aprecian algunas hojas no labradas.

Las hojas de las coronas poseen una ancha base formando las nervaduras una $Y$ invertida. Nervadura central estrecha y otras dos laterales divergentes acabadas en zona de sombra en forma de gota de agua. Lóbulos de cuatro hojitas apuntadas.

Caulículos inclinados con molduras acabadas en semicírculo. Boquilla estriada.

Cáliz abierto en la zona libre del kalathos. De él nace el tallo que sostiene la flor de ábaco. Las hélices son cortas, contraponiéndose al notable desarrollo que adquieren las voluntas.

Abacoliso.

Segunda mitad del siglo II d.C.

\section{Número 2}

Material: Mármol.

Localización: Mezquita.

Medidas: Altura: $42 \mathrm{~cm}$. Abaco: $6 \mathrm{~cm}$. Segunda corona: $22 \mathrm{~cm}$. Corona infer.: $13 \mathrm{~cm}$.

Capitel corintio de columna. Algunas de sus hojas están labradas, encontrándose lisas el resto.

Las hojas labradas tienen una nervadura central flanqueada por dos canales que se aproximan conforme ascienden. Lóbulos de cuatro hojitas apuntadas y carnosas. Zonas de sombra alargadas.

Los caulículos en la zona trabajada tienen molduras acabadas en semicírculos y boquilla diferenciada, no ocurriendo lo mismo en la zona lisa, donde no hay distinción de la boquilla.

Hélices y volutas son lisas.

La flor de ábaco lleva cinco pétalos y botón central.

Abaco liso.

Segunda mitad del siglo II d.C. 


\section{Número 3}

Material: Mármol.

Localización: Mezquita.

Bibliografia: Kühnel (1960), lám. 53, p. 178.

Medidas: Altura: $42 \mathrm{~cm}$. Abaco: $6 \mathrm{~cm}$. Segunda corona: $24 \mathrm{~cm}$. Corona infer.: $13 \mathrm{~cm}$.

Capitel corintio de columna con hojas lisas.

Similares características que la pieza número 4.

Fin del siglo II d.C.

\section{Número 4}

\section{Material: Mármol.}

Localización: Mezquita.

Medidas: Altura: $39 \mathrm{~cm}$. Abaco: $5 \mathrm{~cm}$. Segunda corona: $21 \mathrm{~cm}$. Corona infer.: $11 \mathrm{~cm}$. Capitel corintio de columna con hojas lisas.

Anchas hojas conforman las dos coronas inferiores. Curvatura superior resaltada.

Caulículos estrechos, alargados y algo inclinados. Apenas está marcado el canal que los separa de sus boquillas, que también se encuentran algo inclinadas.

Las hojas alcanzan una altura elevada en el conjunto del capitel, lo que provoca que la zona libre del kalathos sea muy corta aunque ancha. Se decora con cálices abiertos de hojas delgadas, de cuyo centro nace el tallo de la flor de ábaco.

Hélices y volutas anchas, cuyos canales tienen una sección cóncava, y que apenas se ven debido al gran desarrollo de los cálices.

Abaco liso.

Paralelos: Ostia (PENSABENE, 1973, 418), Peruggia (CENCIAIOLI, 1977-78, n. 16-17). Nuestro ejemplar conserva la decoración en la zona libre del kalathos, compuesta por un pequeño cáliz. La disminución de esa zona nos inclina a pensar en un momento tardío del siglo II d.C.

\section{Número 5}

Material: Mármol.

Localización: Mezquita.

Medidas: Altura: $46 \mathrm{~cm}$. Abaco: $6 \mathrm{~cm}$. Segunda corona: $26 \mathrm{~cm}$. Corona infer.: $15 \mathrm{~cm}$. Capitel corintio de hojas lisas.

Dos coronas de ocho hojas que adoptan una posición curvada en el extremo superior.

Caulículos cónicos y levemente inclinados que se introducen en el espacio interfoliar de la segunda corona. Boquilla lisa formada por una moldura.

La zona libre del kalathos se adorna con un cáliz de hojas abiertas en cuyos extremos se sostienen los cálices que soportan las hélices lisas. Lisas son también las volutas, que adoptan un considerable desarrollo dejando un hueco entre el kalathos y el ábaco. 
Abaco liso con un espacio reservado a la flor.

Final del siglo II d.C.

\section{Número 6}

Material: Mármol.

Localización: Mezquita.

Medidas: Altura: $48 \mathrm{~cm}$. Abaco: $6 \mathrm{~cm}$. Segunda corona: $29 \mathrm{~cm}$. Corona infer.: $19 \mathrm{~cm}$.

Capitel corintio de columna con hojas lisas.

La parte inferior de la ima folia no se ha terminado de labrar. Las ocho hojas de cada corona son muy anchas, uniéndose en la parte inferior y curvándose al exterior en la superior.

Volutas anchas, cónicas y lisas. La boquilla es una moldura con poca separación respecto al caule y al cáliz.

La zona libre del kalathos se decora con un cáliz abierto de estrechas hojas que sostienen en sus extremos las hélices. Tanto éstas como las volutan son lisas.

Flor de ábaco desaparecida. Abaco liso.

Finales del siglo II d.C.

\section{Número 7}

Material: Piedra caliza.

Procedencia: C. Rey Heredia.

Localización: Colección particular.

Medidas: Altura: $29 \mathrm{~cm}$. Abaco: $4 \mathrm{~cm}$. Segunda corona: $18 \mathrm{~cm}$. Corona infer.: $9 \mathrm{~cm}$.

Capitel corintio de hojas lisas.

Dos coronas de hojas, la superior más alta que la inferior. Adquieren una forma casi rectangular y se curvan al exterior en el extremo superior de las mismas.

Caulículos estrechos e inclinados en el poco espacio que le dejan las hojas. Boquillas anchas. La zona libre del kalathos se adorna con una hoja lisa corta y ancha. Hélices planas y cortas que corren paralelas al ábaco, al que sostienen. Volutas lisas que adquieren un gran vuelo.

Flor de ábaco grande.

Paralelos: Ostia (PENSABENE, 1973, n. 420).

Principios del siglo III d.C.

\section{Número 8}

Material: Piedra caliza.

Localización: Convento Capuchinas.

Medidas: Altura: $37 \mathrm{~cm}$. Abaco: $7 \mathrm{~cm}$. Segunda corona: $19 \mathrm{~cm}$. Corona infer.: $13 \mathrm{~cm}$. Capitel corintio de columna con hojas lisas. 
Las hojas que forman las coronas son anchas, altas y curvan sus extremos hacia el exterior.

En la secunda folia, aprovechando los huecos interfoliares, se clavan unos macizos y cónicos caulículos con unas gruesas boquillas. Cálices potentes que sostienen las volutas. Las hélices tocan sus extremos y se encuentran caídas por debajo de una potente flor de ábaco.

Primera mitad del siglo III d.C.

\section{Número 9}

Material: Mármol.

Localización: Museo.

Medidas: Altura: $24 \mathrm{~cm}$. Abaco: $3 \mathrm{~cm}$. Segunda corona: $12 \mathrm{~cm}$. Corona inferior: $7 \mathrm{~cm}$. Capitelito de columna de hojas lisas.

Doble corona de hojas, alcanzando la primera mayor altura que la segunda. Son hojas planas, pegadas al kalathos que curvan sus extremos al exterior.

Caulículos cónicos, rectos, diferenciando claramente su boquilla. Hélices y volutas poseen un similar desarrollo horizontal y no en vertical. Ambos elementos se encuentran en el mismo nivel.

Paralelos: Itálica (THOUVENOT, 1938, fig. 4, p. 80); Ostia (PENSABENE, 1973, n. 429).

Hélices y volutas comienzan a adoptar una disposición longitudinal y se encuentran en el mismo plano.

Segunda mitad del siglo III o siglo IV d.C.

\section{Número 10}

Material: Piedra caliza.

Localización: Museo.

Medidas: Altura: $36 \mathrm{~cm}$. Abaco: $4 \mathrm{~cm}$. Segunda corona: $18 \mathrm{~cm}$. Corona inferior: $9 \mathrm{~cm}$.

Capitel corintio de hojas lisas.

Las dos coronas se encuentran muy pegadas al kalathos, con poco relieve incluso en el tercio superior de las hojas.

Caulículos cortos e inclinados, con una ancha boquilla. Apenas queda espacio para decorar la zona libre del kalathos dado que por un lado las hojas ascienden mucho, y por otra parte, las hélices están muy inclinadas y sostienen un fuerte peso. En estas últimas se observa el poco detalle y cuidado que se ha tenido a la hora de la realización de la pieza.

Cáliz ancho que ha desaparecido en los extremos junto con las volutas.

Flor de ábaco muy destruida.

Algunos elementos nos dan la clave para fechar esta pieza: hélices caídas por el peso 
que soportan. La hoja lisa que adorna la zona libre del kalathos apenas tiene espacio para su desarrollo. Volutas poco definidas.

Siglo III d.C. avanzado.

\section{Número 11}

Material: Mármol.

Localización: Mezquita.

Medidas: Altura: $40 \mathrm{~cm}$. Abaco: $4 \mathrm{~cm}$. Segunda corona: $20 \mathrm{~cm}$. Corona inferior: $9 \mathrm{~cm}$. Capitel corintio de columna con hojas lisas.

Este ejemplar difiere sustancialmente de los otros vistos hasta ahora en la Mezquita desde un punto de vista morfológico: posee un kalathos más esbelto; las coronas están formadas por ocho hojas con clara tendencia a adoptar una forma rectangular y una más que acusada curvatura en el extremo superior de la hoja.

Los caulículos son estrechos y cónicos. Su boquilla apenas adquiere independencia respecto al caule. Los cálices destacan poco y se hallan literalmente pegados al kalathos en la parte baja y a las hélices y volutas en la superior.

La zona libre no se decora. El ábaco es liso y en su centro se deja un paralelepípedo para la flor de ábaco.

Paralelos en Mérida (BARRERA ANTON 1982, 34-35, n. 3). Véase (CRESSIER 1984, p. 228, lám. 72-e).

Siglo IV d.C.

\section{Número 12}

Material: Mármol.

Localización: Mezquita.

Medidas: Altura: $44 \mathrm{~cm}$. Abaco: $5 \mathrm{~cm}$. Segunda corona: $19 \mathrm{~cm}$. Corona infer.: $10 \mathrm{~cm}$. Capitel corintio de columna con hojas lisas.

Similares características a la pieza anterior.

Siglo IV d.C.

\section{Número 13}

Material: Mármol.

Localización: Iglesia de S. Lorenzo.

Medidas: Altura: $31 \mathrm{~cm}$. Abacc: $5 \mathrm{~cm}$. Segunda corona: $17 \mathrm{~cm}$. Corona infer.: $10 \mathrm{~cm}$.

Capitel corintio de columna de hojas lisas. La zona libre del kalathos es reducida y se amplía por el contrario el ábaco, que en este caso sí está sometido por hélices y voluta. Muy parecido a uno citado por Díaz Martos (1985, I-11, p. 155).

Siglo V d.C. 


\section{Bibliografia}

BARRERA, J.L. (1982). “Capiteles romanos del Museo de Badajoz”. Museos, 1,3336.

BARRERA, J.L. (1984). "Los capiteles romanos de Mérida". Monografías emeritenses 2 .

BERMUDEZ, J.M. et alii. (1991). “Avances de resultados del seguimiento arqueológico de remociones de tierra en el solar de la C. Ambrosio de Morales, 4. Córdoba”. Antiquitas, 2, en prensa.

CENCIAIOLI, L. (1977-78). "I capitelli romani di Peruggia". Annali della Facoltà di Lettere e Filosofia. Studi Classici, I, 41-96.

COARELLI, F. (1981). L'Area Sacra di Largo Argentina. Roma.

CRESSEDI, L. (1952). “'Origine e sviluppo del capitello a foglie lisce”. Bolletino del Centro di Studi di Storia dell' architettura, 6, 9-12.

CRESSIER, P. (1984). "Les chapiteaux de la Grande Mosquée de Cordoue (oratoire d'Abd-Ar-Rahman I et d'Abd-Ar-Rahman II) et la sculpture des chapiteaux à l'époque èmirale". MM. 25, 216-281.

CHINER, P. (1990). La Decoración Arquitectónica en Saguntum. Valencia.

DIAZ MARTOS, A. (1985). Capiteles corintios romanos de Hispania. Estudio-Catálogo. Madrid.

GUTIERREZ BEHEMERID, M.A. (1982). " Sobre la sistematización del capitel corintio en la Península Ibérica”. BSAV XLVIII, 25-44.

HARRAZI, N. (1982). Chapiteaux de la Grande Mosquée de Kairouan. Tunis.

KUHNEL, E. (1960). “Antike und orient als Quellen der Spanisch-islamischen Kunst". MM. 1, 174-181.

MARQUEZ, C. (1990). Los Capiteles romanos de Colonia Patricia Corduba. Tesis Doctoral, Universidad de Córdoba (inédita).

PENSABENE, P. (1973). Scavi di Ostia. VII. I Capitelli. Roma.

PENSABENE, P. (1982). Les chapiteaux de Cherchel. Etude de la décoration arquitectonique. 3 Supp. Bulletin d'Archéologie Algérienne.

RECASENS, M. (1979). "'Los capiteles romanos del Museu Nacional Arqueologic de Tarragona". Extret del Butlleti Arqueologic, 1, 43-143.

SECILLA, R.-MARQUEZ, C. (1988). "'Una casa romana en el SE de Colonia Patricia Corduba". Coloquio 'La Casa Urbana Hispano-romana", Zaragoza, en prensa.

THOUVENOT, R. (1938). "Chapiteaux romains tardifs de Tingitane et d'Espagne". Public. Serv. Antiqu. Maroc. 3, 63-82.

VENTURA, A. (1991). " Resultados del seguimiento arqueológico en el solar de la C. Angel de Saavedra 10, Córdoba”'. Anales de Arqueología Cordobesa, II. 


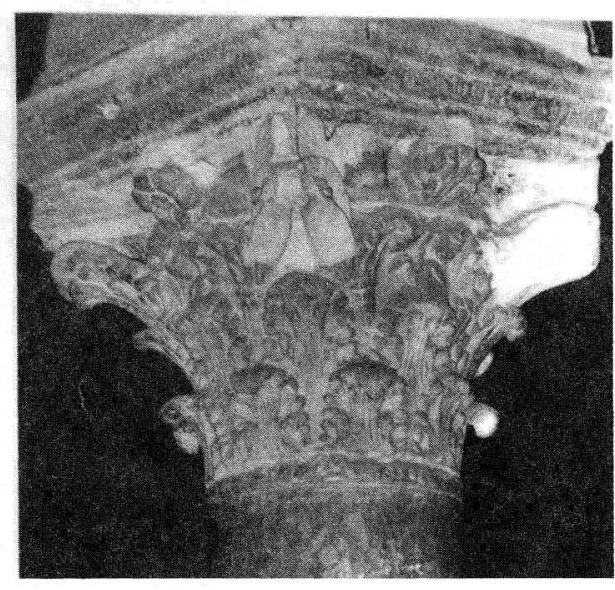

Número 1-A

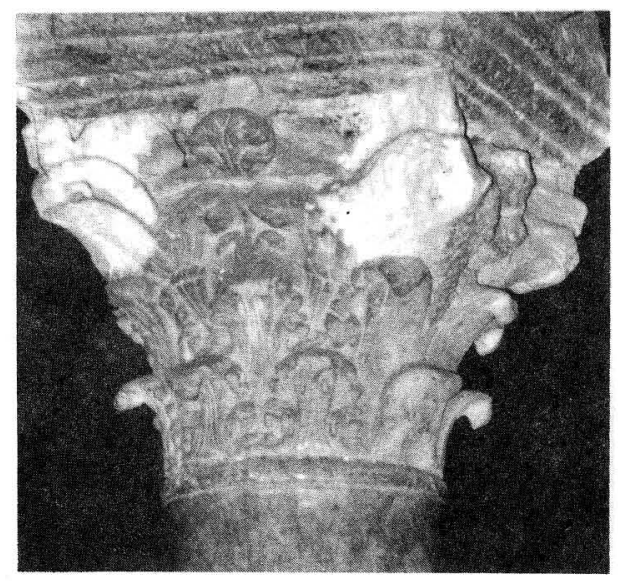

Número 1-B

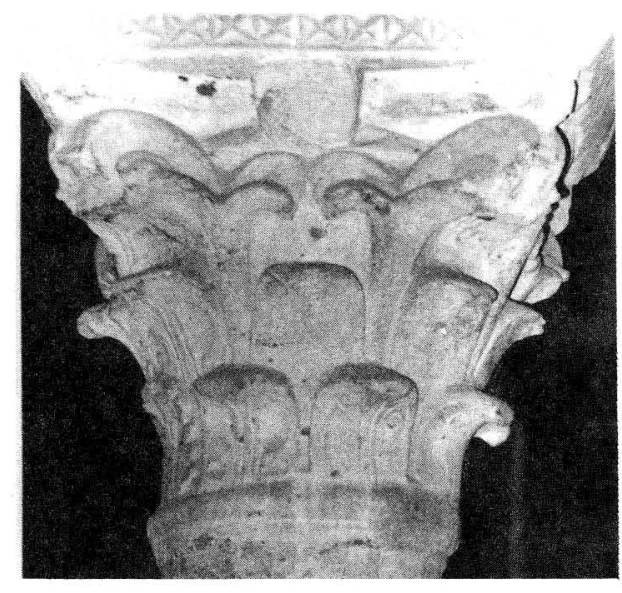

Número 2-A

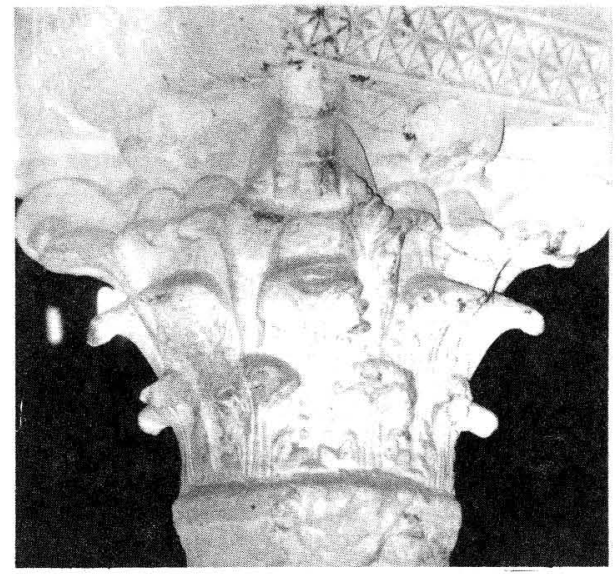

Número 2-B

\section{Lámina I}




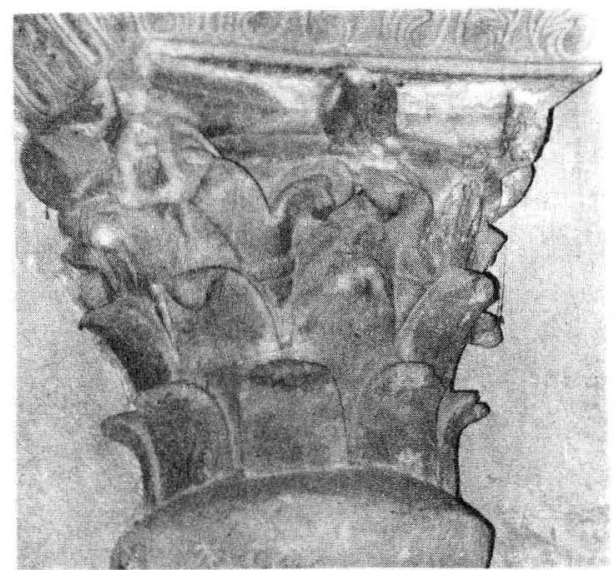

Número 3

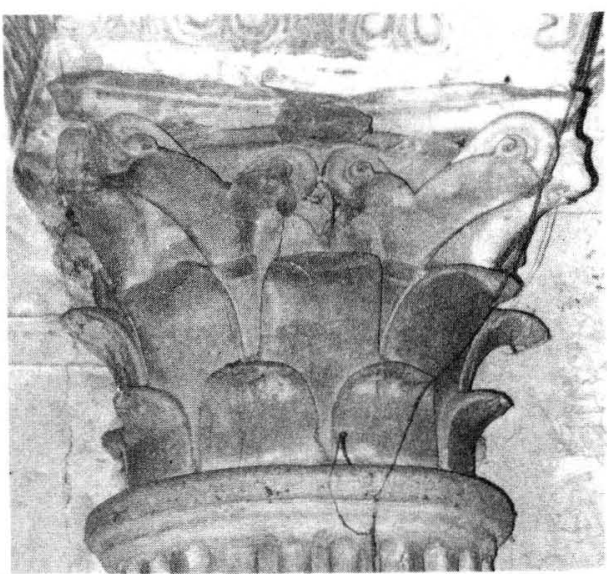

Número 4

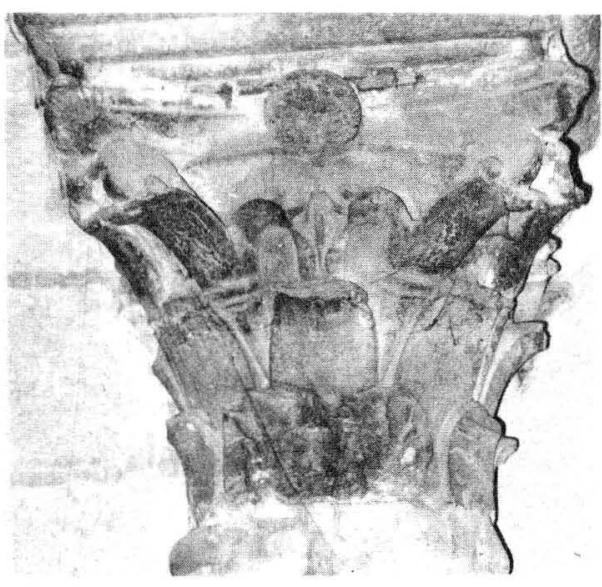

Número 5

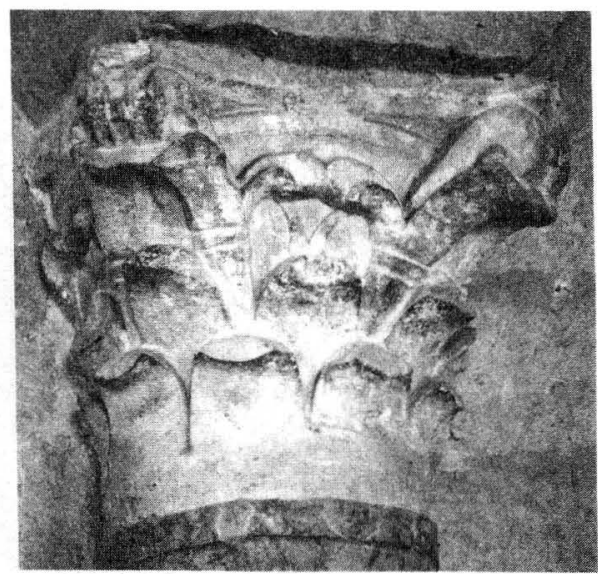

Número 6

\section{Lámina II}




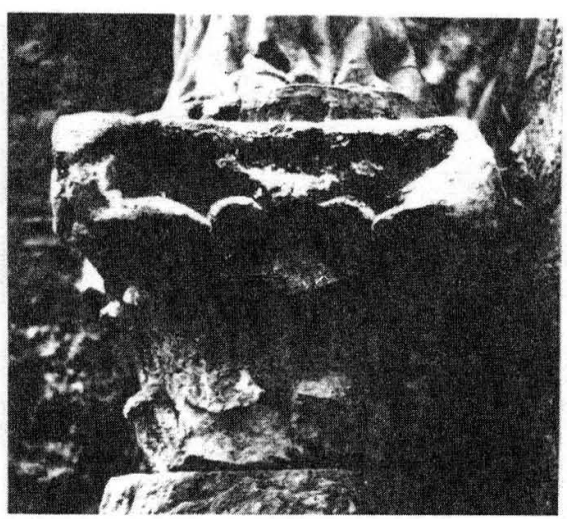

Número 7

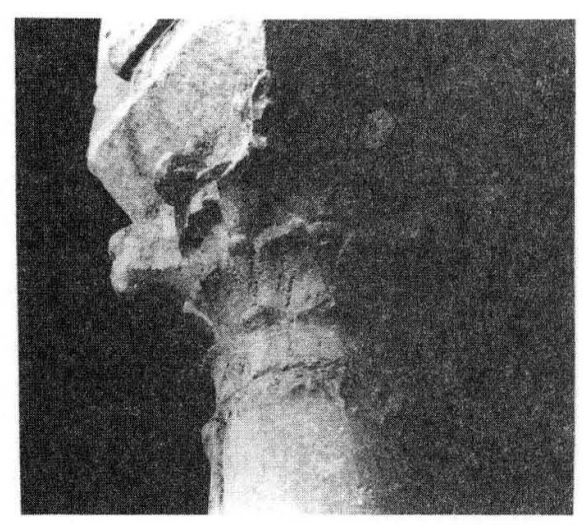

Número 8

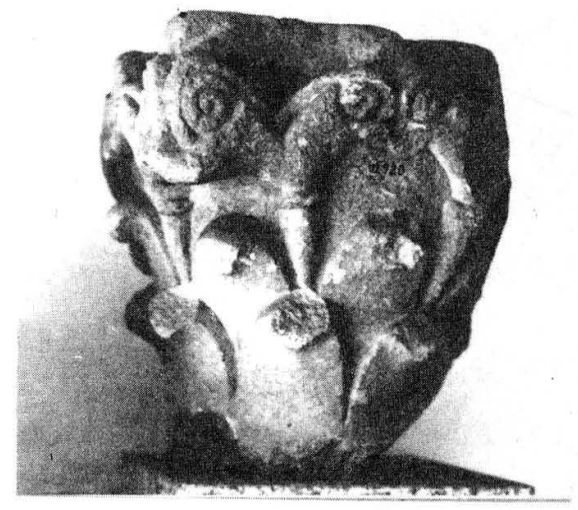

Número 9

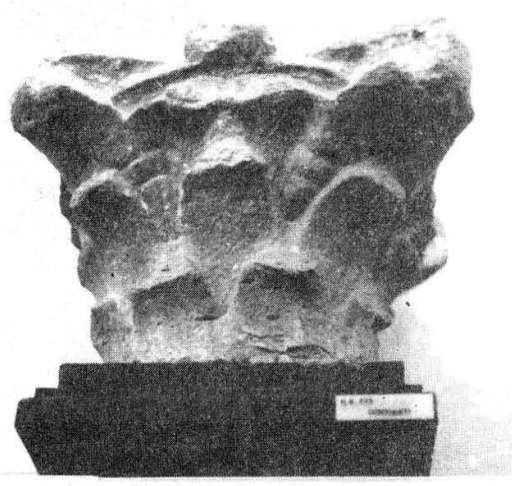

Número 10

\section{Lámina III}




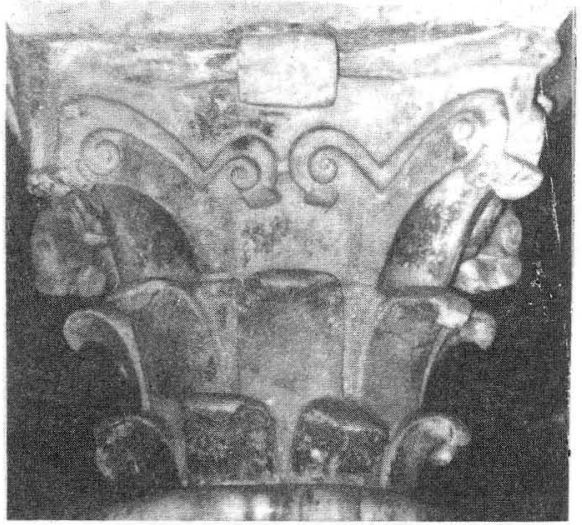

Número 11

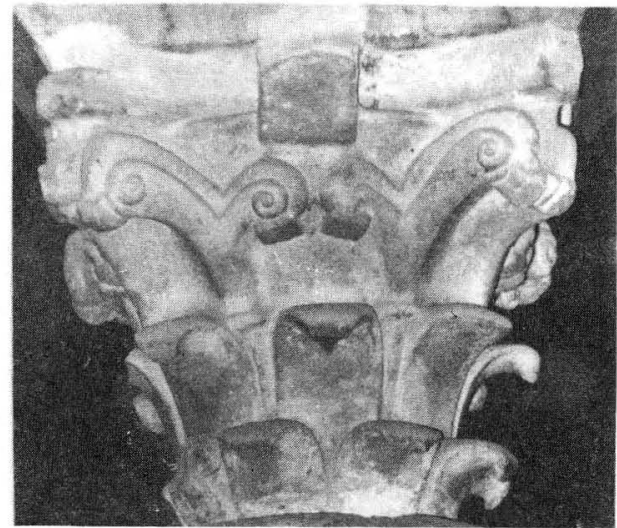

Número 12

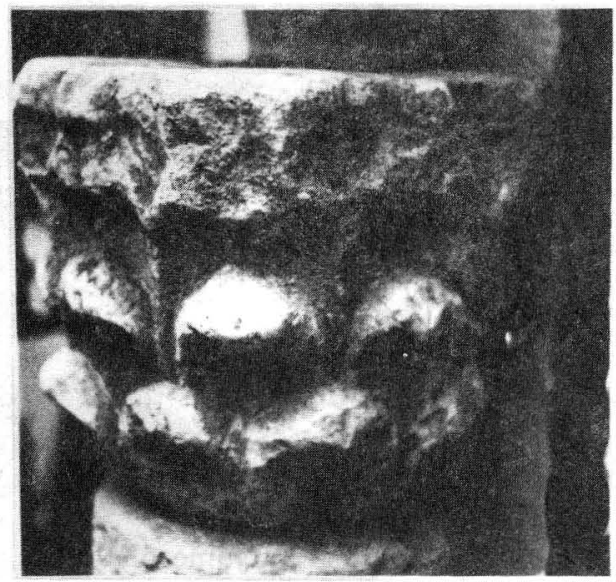

Número 13

\section{Lámina IV}




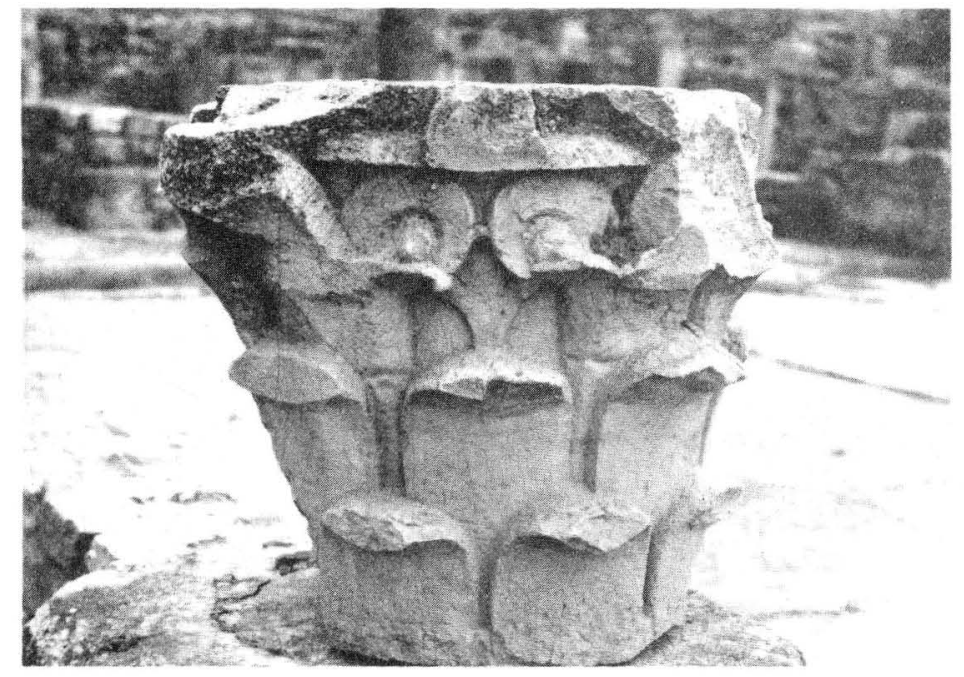

Número 14. Bulla Regia. Casa de la Caza

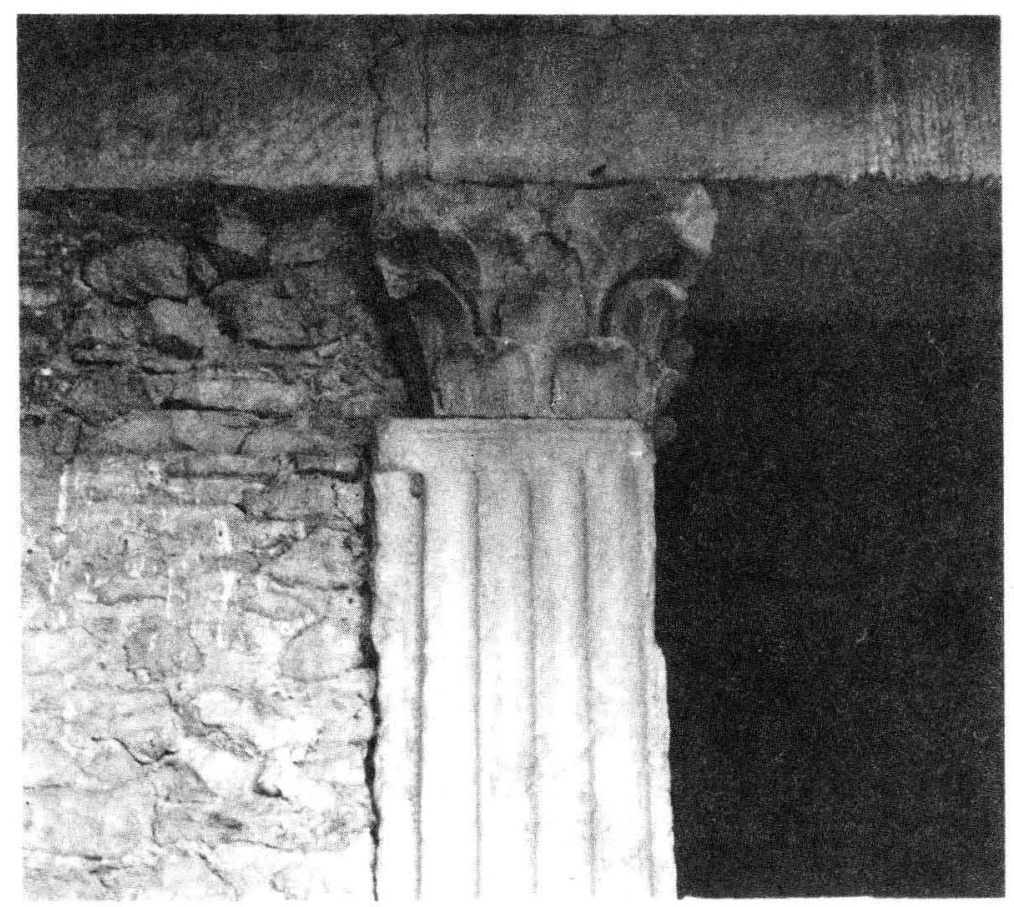

Número 15. Bulla Regia. Casa de la Caza

\section{Lámina V}




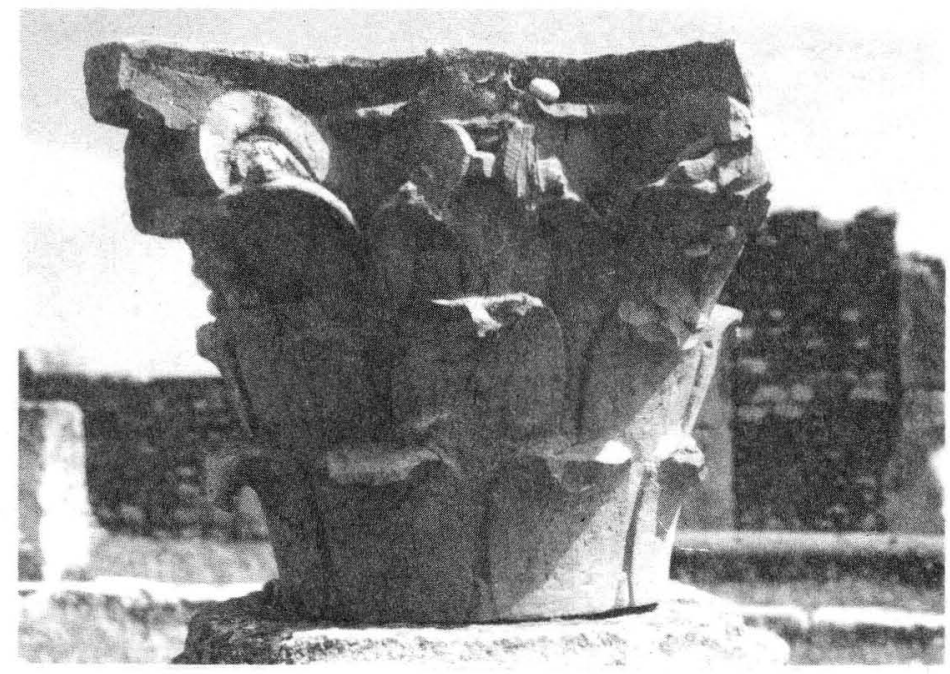

Número 16. Bulla Regia. Capitel

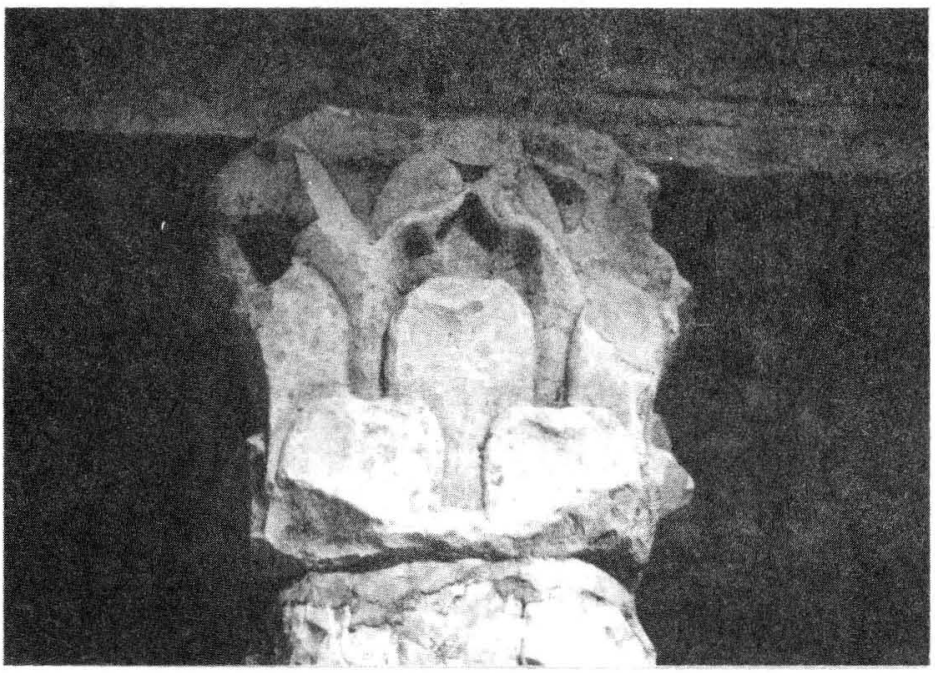

Número 17. Bulla Regia. Capitel. Casa del Anfitrite

\section{Lámina VI}

